\title{
SOX after SOX: SOXession regulates neurogenesis
}

\author{
Michael Wegner ${ }^{1}$ \\ Institut für Biochemie, Emil-Fischer-Zentrum, Friedrich-Alexander-Universität Erlangen-Nürnberg, \\ 91054 Erlangen, Germany
}

Vertebrate embryonic stem (ES) cells give rise to many different cell types in multistep processes. These involve the establishment of a competent state, specification, differentiation, and maturation, and often involve Sox transcription factors. In this issue of Genes \& Development, Bergsland and colleagues (pp. 2453-2464) determine the genome-wide binding profile of Sox2, Sox3, and Sox11 as ES cells become specified to neural precursors and differentiate into neurons. An ordered, sequential binding of these Sox proteins to a common set of gene enhancers was found to drive neurogenesis, as Sox proteins first help to preselect neural genes in ES cells and later ensure their proper activation in neural precursors or neurons.

Pioneer factors and gene preselection in embryonic stem (ES) cells

A unique set of transcription factors is required to establish ES cells and keep them in a pluripotent and proliferative state. Equally unique is the chromatin state in ES cells, in which DNA is less tightly associated with core histones and heterochromatin protein 1 than in other cells (Meshorer et al. 2006; Ram and Meshorer 2009; Smale 2010). This open chromatin structure depends on the remodelling activity of Chd1 (Gaspar-Maia et al. 2009) and allows for the low-level expression of many genes, including those that are later predominantly or exclusively expressed in specific tissues or cell types (Guenther et al. 2007; Efroni et al. 2008). Enhancers of tissue-specific genes coincide with windows of unmethylated DNA in ES cell chromatin (Xu et al. 2009) and exhibit a bivalent chromatin signature characterized by the joint presence of active chromatin marks, such as $\mathrm{H} 3 \mathrm{~K} 4 \mathrm{me} 3$, and repressive ones, such as H3K27me3, due to the activity of Polycomb complexes (Mikkelsen et al. 2007; Ku et al. 2008). This bivalent chromatin signature likely represents a poised state that is convertible into an

[Keywords: lineage formation; neural development; neural stem cells; Sox genes]

${ }^{1}$ Correspondence.

E-mail m.wegner@biochem.uni-erlangen.de.

Article is online at http://www.genesdev.org/cgi/doi/10.1101/gad.181487.111. active one by removal of the repressive marks and is a hallmark of regulatory regions associated with genes whose products have to be activated once stem cells lose pluripotency and develop into defined cell types through consecutive stages of specification and differentiation (Ram and Meshorer 2009; Smale 2010). Transcriptional competence for particular developmental pathways is thus already established in ES cells.

The same cell type-specific regulatory regions are also bound by pioneer transcription factors. These factors recognize and influence the chromatin state and may thus be instrumental in establishing or maintaining the poised state (Smale 2010; Magnani et al. 2011). For eventual enhancer activation in the context of a developmental program, pioneer factors then get replaced and lineage-specific transcription factors take over. In the case of the well-studied albumin gene, the pioneer factor FoxD3 occupies the liver-specific enhancer in ES cells and is replaced by FoxA1 once cells commit to the endoderm lineage (Xu et al. 2009).

\section{Functional dichotomy of Sox2 in ES cells}

ES cells express the Sox2 transcription factor, which, together with the closely related Sox 1 and Sox3 proteins, forms the SoxB1 subgroup of the Sox protein family (Fig. 1A; Schepers et al. 2002; Guth and Wegner 2008). Sox2 is required for establishing ES cells, maintaining their pluripotency, and ensuring self-renewal (Avilion et al. 2003). It is also part of the transcription factor combination that is capable of re-establishing pluripotent stem cell characteristics in terminally differentiated cells (Takahashi and Yamanaka 2006). In combination with other ES cell transcription factors, such as Oct4, Sox2 is found on the regulatory regions of many genes with ES cell-specific expression (Fig. 1B; Boyer et al. 2005; Chen et al. 2008; Marson et al. 2008). Additionally, Sox2 binds to several other sites in the genome, arguing that it may also function as a pioneer factor in ES cells. In accord with such a function, Sox 2 has recently been found in ES cells on several enhancers that become activated only later during B-cell development (Liber et al. 2010). By the time of activation, Sox2 is no longer present and has been replaced by Sox 4 as the transcription factor that finally induces these enhancers in differentiating B cells. Sox 4 is 


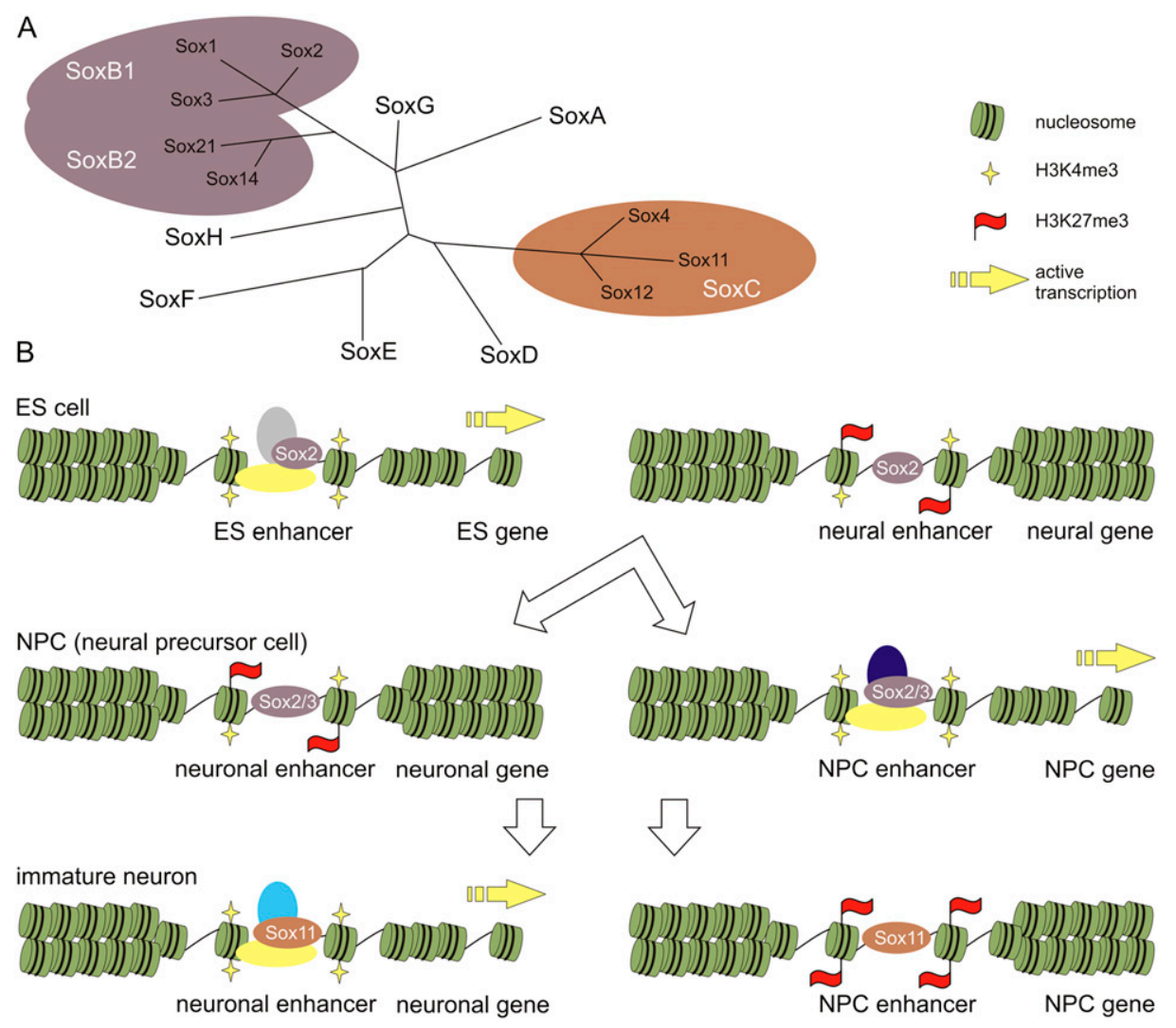

Figure 1. Relationship, expression, and activities of Sox factors involved in neurogenesis. $(A)$ The Sox family tree with its various subgroups. Members are only listed for the SoxB1, SoxB2, and SoxC subgroups. (B) Summary of the findings by Bergsland et al. (2011). In ES cells, Sox 2 binds ES cell-specific and neural enhancers. The ES cell-specific enhancers are marked by H3K4me3 and activated by Sox2, whereas the neural enhancers carry both H3K4me3 and H3K27me3 marks and are silent. Upon specification to NPCs, Sox2 may be replaced on neural enhancers by other SoxB1 proteins, such as Sox3. Neural enhancers bound by Sox2 or Sox3 (Sox2/3) are again either marked by H3K4me3 or carry both H3K4me3 and H3K27me3 marks. The former correspond to SoxB1-activated NPC enhancers, and the latter remain silent in NPCs. After neuronal differentiation, both types of enhancers exchange their SoxB1 factors for SoxC factors, including Sox11. The NPC enhancers acquire H3K27me3 and are inactive, whereas the previously poised enhancers with bivalent histone marks convert to a monovalent chromatin signature with H3K4me3 only and are active as neuronal enhancers.

also a member of the Sox family of transcription factors. However, it is only distantly related to Sox 2 and is not a member of the SoxB1 subgroup (Schepers et al. 2002; Guth and Wegner 2008). Instead, Sox4 forms the separate SoxC subgroup with Sox11 and Sox12 (Fig. 1A).

\section{Sox transcription factors in neurogenesis}

Although Sox 2 is best known for its role in ES cells, it has numerous other functions during development, including a prominent one in neurogenesis (Wegner and Stolt 2005; Pevny and Nicolis 2010). Sox2 is strongly expressed throughout the early neuroectoderm and in neural precursor cells (NPCs) (Collignon et al. 1996; Ferri et al. 2004). In fact, it can still be found in NPCs that persist as neural stem cells in the neurogenic niches of the adult brain (Ferri et al. 2004; Favaro et al. 2009). In most NPCs, Sox 2 becomes down-regulated during the final cell cycle immediately before differentiation, so that it can no longer be found in immature neurons. Sox 2 is required for the maintenance of NPC properties and functions, at least in part, through the Shh and Notch pathways (BaniYaghoub et al. 2006; Taranova et al. 2006; Favaro et al. 2009). Its importance in NPCs is evident from electroporation studies in the chicken neural tube (Bylund et al. 2003; Graham et al. 2003). Overexpression of Sox2 kept cells in a precursor state and prevented the up-regulation of neuronal markers by interfering with the function of proneural genes, whereas overexpression of a dominantnegative version of Sox 2 caused the cells to leave the cell cycle, turn on neuronal markers, and differentiate prematurely. Indeed, deletion of Sox 2 in the mouse attenuates the self-renewal capacity. As a result, neural stem cells are completely lost from the early postnatal hippocampus (Favaro et al. 2009). However, depletion of the stem cell pool is delayed, and not all NPCs in the brain are equally affected (Miyagi et al. 2008). In this context, it is important to note that mammalian ES cells turn on Sox3 and Sox 1 once they commit to the neural lineage. As a consequence, Sox2 expression in NPCs overlaps substantially with expression of these closely related SoxB1 factors (Collignon et al. 1996; Pevny et al. 1998; Miyagi et al. 
2008). It is thus likely that the three SoxB1 factors share common functions and act, at least in part, redundantly. In support of this conclusion, overexpression of the three SoxB1 proteins in the electroporated chicken neural tube led to very similar results (Bylund et al. 2003; Graham et al. 2003).

Eventually, SoxB1 factors and activities have to be down-regulated in NPCs for neurogenesis to proceed. There is evidence of an involvement of proneural genes (Bylund et al. 2003; Graham et al. 2003), which, among other targets, induce Sox21 (Sandberg et al. 2005). Sox 21 and Sox14 form the SoxB2 sister group to the SoxB1 proteins (Fig. 1A; Schepers et al. 2002; Guth and Wegner 2008). Whereas SoxB1 factors seem to act predominantly as transcriptional activators, Sox 21 has repressor activity (Uchikawa et al. 1999). On the basis of electroporation experiments in the chicken neural tube, a model has been proposed in which Sox21, once induced in NPCs, counteracts the activity of SoxB1 proteins and allows the cells to progress to immature neurons (Sandberg et al. 2005). Presumably, this involves repression of the same target genes that are normally induced by SoxB1 proteins in NPCs.

The SoxC factors (Sox4 and Sox11) are another set of Sox factors that are induced by proneural proteins as NPCs develop into immature neurons (Bergsland et al. 2006). As the third SoxC protein, Sox 12 is likely induced as well, but is functionally less prominent (Hoser et al. 2008). When assessed in the chicken neural tube by electroporation studies, SoxC function contrasts sharply with SoxB1 or SoxB2 function, as overexpression of Sox 4 or Sox11 led to precocious induction of neuronal markers (Bergsland et al. 2006). Deletion of Sox 4 or Sox 11 in mice, in contrast, had little consequences on neurogenesis, arguing that SoxC proteins function redundantly in this process (Cheung et al. 2000; Sock et al. 2004). In accord with such an assumption, simultaneous deletion of both SoxC factors led to massive apoptosis throughout the developing nervous system that predominantly affected immature neurons (Bhattaram et al. 2010; Thein et al. 2010).

In summary, these studies argue that neurogenesis crucially depends on several different Sox proteins and that these Sox proteins have to act in a strictly defined temporal order, with Sox 2 already being present in ES cells and other SoxB1 factors joining Sox 2 in NPCs before Sox 21 helps to leave the NPC stage and SoxC proteins induce neuronal differentiation.

\section{Sequential enhancer occupancy by Sox proteins during neurogenesis}

While this model for the role of Sox proteins in neurogenesis is fairly detailed, it provides very little mechanistic insight. In particular, it remains largely unknown to what extent the activity of Sox2 in ES cells relates to its activity in NPCs, or to what extent the activity of SoxB factors in NPCs impacts SoxC protein activity in immature neurons. The study by Bergsland et al. (2011) in this issue of Genes \& Development fills this gap.
Using established ES cell differentiation protocols, Bergsland et al. (2011) generated NPCs and young neurons in culture. They then performed chromatin immunoprecipitation (ChIP) with antibodies against Sox2, Sox3, and Sox 11 and determined the genome-wide binding pattern for each of these factors in NPCs and young neurons by ChIP combined with massively parallel sequencing (ChIP-seq). Comparison with the known binding pattern of Sox 2 in ES cells (Chen et al. 2008; Marson et al. 2008) and expression profiles from ES cells led to several important and remarkable conclusions.

First of all, Bergsland et al. (2011) found that the genome-wide binding patterns of Sox 2 and Sox 3 in NPCs overlap extensively, with $96 \%$ of the Sox 2 -bound sites also bound by Sox3. This impressively confirms the assumed functional redundancy of SoxB1 proteins in NPCs on a genome-wide level. Bergsland et al. (2011) also report a good correlation between Sox3-binding sites and regions bound by the p300 coactivator in the embryonic brain. Therefore, a substantial number of the identified binding sites are part of brain-specific regulatory regions. From their position relative to the associated genes, most regions are enhancers rather than promoters.

Comparison of the binding profile of Sox 2 in ES cells with that of Sox3 in NPCs /which is very similar to the Sox2-binding pattern in NPCs and thus paradigmatic for the SoxB1-binding pattern) confirmed that there are binding sites in ES cells that are not occupied by SoxB1 proteins in NPCs. These binding sites were enriched in the vicinity of genes with ES cell-specific expression and likely correspond to ES cell enhancers. Additionally, there was also a large number of binding sites that were recognized by both Sox 2 in ES cells and Sox 3 in NPCs. These binding sites were preferentially located near neural genes, including genes already known as (or presumed to be) SoxB1 targets. Many of these sites were also associated with bivalent histone domains that carried both $\mathrm{H} 3 \mathrm{~K} 4 \mathrm{me} 3$ and H3K27me3 marks and likely correspond to neural enhancers that are preselected by Sox 2 in ES cells for future activation during neural development (Fig. 1B). The study therefore confirms Sox 2 as a pioneer factor that establishes transcriptional competence for neural development in ES cells.

Intriguingly, Bergsland et al. (2011) also found that the genome-wide binding profile of Sox 3 in NPCs extensively overlaps with the genome-wide binding profile of Sox 11 in young neurons. In fact, only $8 \%$ of the Sox 11 targets are not bound by Sox 3 , and just $30 \%$ of the Sox 3 targets are not recognized by Sox11. Further bioinformatic analysis indicated that selective occupation by either factor is restricted to genes that are predominantly expressed in late populations of neurons and glia. This correlates with the finding that SoxB1 factors eventually reappear during late phases of neurogenesis in select and largely nonoverlapping populations of mature neurons, where they perform functions that are unrelated to the earlier ones in NPCs (Malas et al. 2003; Ferri et al. 2004).

In contrast, the overlapping targets correspond to genes that are expressed in either NPCs or young, immature neurons. Bergsland et al. (2011) provided evidence from 
expression profiling of Sox3-overexpressing NPCs and from the detailed functional characterization of several enhancers identified in their ChIP-seq study that both Sox3 and Sox11 overwhelmingly act as transcriptional activators. Sox3, however, activates only the fraction of genes expressed in NPCs, whereas the identified neuronspecific enhancers are selectively activated by Sox11.

This argues that SoxB1 factors (exemplified by Sox3) bind not only to regulatory regions of genes that are activated by these factors in NPCs, but also to regulatory regions of genes that are later activated by SoxC proteins (exemplified by Sox11) in immature neurons. The analysis of representative regulatory regions from both groups further indicates that the two groups are characterized by different chromatin signatures. In NPCs, SoxB1-activated enhancers are solely marked by $\mathrm{H} 3 \mathrm{~K} 4 \mathrm{me} 3$, while not-yetactive neuron-specific enhancers carry both $\mathrm{H} 3 \mathrm{~K} 4 \mathrm{me} 3$ and H3K27me3 marks (Fig. 1B). SoxB1 factors may thus also function as pioneer factors in NPCs by keeping neuronal enhancers in a silent but poised state for activation. Some of the neuronal maturation defects observed in mouse models with SoxB1 gene deletions may actually be caused by such a compromised pioneer factor function (Cavallaro et al. 2008). SoxB1 factors may additionally exert their function by sterically interfering with SoxC protein binding during the short time of coexpression in late NPCs and may thereby prevent precocious activation of neuronal enhancers.

If the same enhancers are studied in young neurons instead of NPCs, their chromatin signature has changed such that the neuron-specific enhancers only possess H3K4me3 marks, and the NPC-specific ones exhibit only the $\mathrm{H} 3 \mathrm{~K} 27 \mathrm{me} 3$ mark characteristic of the inactivated state (Fig. 1B). Considering that the active neuronal and the inactive NPC enhancers are occupied by Sox11 in young neurons, it seems plausible to assume that Sox11 is not only involved in activating the neuronal enhancers, but may also help to shut off the NPC enhancers. Whether this involves a direct influence on the chromatin state is not known at the moment. What Bergsland et al. (2011) have shown, however, is that the presence of Sox3 alters the chromatin state of neuronal enhancers in nonneural cells from an inactive to a poised one, thus confirming - at least for Sox3-a direct influence on the chromatin state.

Neurogenesis thus depends on the ordered succession of a defined group of Sox proteins on a common set of target gene enhancers, with at least some of these Sox proteins functioning not only as stage-specific transcriptional activators, but also as pioneer factors with an impact on chromatin structure and the epigenetic state (Fig. 1B). Sox2 already preselects neural enhancers in ES cells and thereby establishes neural competence. It is then directly involved with other SoxB1 proteins in the conversion of ES cells into NPCs. During this specification, Sox2 either stays on the neural enhancers or gets replaced by other SoxB1 factors, such as Sox3. Jointly, they activate NPC-specific genes or again preselect as pioneer factors those genes that become activated by SoxC proteins once NPCs convert into neurons. Intrigu- ingly, this Sox factor relay model of neurogenesis uses more highly related Sox factors than the one previously identified for the selection and activation of B-cell-specific enhancers during lymphocytic differentiation of ES cells (Liber et al. 2010).

\section{Unsolved issues, future directions, and implications beyond neurogenesis}

As intriguing and fascinating as these findings are, they also raise questions. Considering that all Sox proteins have very similar DNA recognition motifs (Wegner 2010), it seems possible that SoxC proteins and SoxB1 proteins bind to the exact same sites in the enhancers. Support for such an assumption comes from the prediction of single Sox-binding sites in many of the identified enhancers. However, Sox-binding sites are difficult to predict. Considering further that slightly different binding site preferences exist among Sox proteins, and that many other enhancers contain multiple Sox-binding sites (Wegner 2010), the reported succession of Sox proteins may be more complex than a simple exchange on the exact same site.

It also needs to be remembered that the current picture does not yet include the SoxB2 protein Sox21, despite its proposed role as a direct antagonist of SoxB1 proteins in NPCs. To see how Sox 21 fits in, it would be interesting to determine its genome-wide binding pattern as well. Another limitation of the current model stems from the fact that it only determines binding profiles until shortly after neuron formation. The analyzed neurons are still relatively immature and strongly express SoxC proteins. Once they mature, they lose SoxC expression /Cheung et al. 2000; Sock et al. 2004; Bergsland et al. 2006; Thein et al. 2010). SoxC factors can therefore only be responsible for the induction and the early phases of neuronal gene expression, but not for maintenance. Thus, it would be interesting to know whether SoxC proteins are followed by yet another group of Sox proteins or whether Sox proteins are simply not that important for the final phases of neuronal maturation.

Also implicit in the findings of Bergsland et al. (2011) is that Sox protein function is strongly context-dependent and that there must be features other than their temporal expression patterns that determine the activity of a particular Sox protein on a specific enhancer at a given time. Sox2, for instance, must be able to differentiate in ES cells between those enhancers that it activates and those that it keeps in a poised state. The same holds true for Sox3 in NPCs; even Sox11 has to distinguish between the enhancers it activates in immature neurons and those that it does not, despite binding. As minor groove binders, Sox proteins generally cooperate with major groove-binding transcription factors to activate enhancers (Kamachi et al. 2000; Wegner 2010). The POU factor Oct4 is such a partner for Sox 2 in ES cells. It is safe to assume that cooperating transcription factors will also influence Sox protein function during neurogenesis. Among others, these factors include members of the POU family, such as Brn1 and Brn2. Determination of their genome-wide binding pattern and comparison with the Sox-binding 
profile will therefore be instrumental in further clarifying the regulatory circuits during neurogenesis.

Finally, attention needs to be drawn to the architectural function of Sox proteins (Werner and Burley 1997). Sox proteins induce dramatic topological alterations upon binding of their high-mobility group domain to the minor groove of their target DNA. This may be generally relevant in the context of chromatin and for the change of chromatin states. Considering that Bergsland et al. (2011) provided ample evidence that some Sox proteins read chromatin states as pioneer factors and may influence chromatin signatures by triggering changes in histone modifications, it will be interesting to see how common this link is and how widespread pioneer factor functions are among Sox proteins. Their architectural role certainly predisposes Sox proteins for a role in recognizing and changing chromatin environments.

\section{Acknowledgments}

Work in my laboratory is supported by grants from IZKF Erlangen, Deutsche Forschungsgemeinschaft, ForNeuroCell 2, and Fonds der Chemischen Industrie.

\section{References}

Avilion AA, Nicolis SK, Pevny LH, Perez L, Vivian N, LovellBadge R. 2003. Multipotent cell lineages in early mouse development depend on SOX2 function. Genes Dev 17: 126140.

Bani-Yaghoub M, Tremblay RG, Lei JX, Zhang D, Zurakowski B, Sandhu JK, Smith B, Ribecco-Lutkiewicz M, Kennedy J, Walker PR, et al. 2006. Role of Sox2 in the development of the mouse neocortex. Dev Biol 295: 52-66.

Bergsland M, Werme M, Malewicz M, Perlmann T, Muhr J. 2006. The establishment of neuronal properties is controlled by Sox4 and Sox11. Genes Dev 20: 3475-3486.

Bergsland M, Ramsköld D, Zaouter C, Klum S, Sandberg R, Muhr J. 2011. Sequentially acting Sox transcription factors in neural lineage development. Genes Dev (this issue). doi: 10.1101/gad.176008.111.

Bhattaram P, Penzo-Méndez A, Sock E, Colmenares C, Kaneko KJ, DePamphilis ML, Wegner M, Lefebvre V. 2010. Organogenesis relies on Sox4, Sox11, and Sox12 for survival of neural and mesenchymal progenitor cells. Nat Commun 1:9. doi: $10.1038 /$ ncomms 1008 .

Boyer LA, Lee TI, Cole MF, Johnstone SE, Levine SS, Zucker JP, Guenther MG, Kumar RM, Murray HL, Jenner RG, et al. 2005. Core transcriptional regulatory circuitry in human embryonic stem cells. Cell 122: 947-956.

Bylund M, Andersson E, Novitch BG, Muhr J. 2003. Vertebrate neurogenesis is counteracted by Sox1-3 activity. Nat Neurosci 6: 1162-1168.

Cavallaro M, Mariani J, Lancini C, Latorre E, Caccia R, Gullo F, Valotta M, Debiasi S, Spinardi L, Ronchi A, et al. 2008. Impaired generation of mature neurons by neural stem cells from hypomorphic Sox2 mutants. Development 135: 541-557.

Chen X, Xu H, Yuan P, Fang F, Huss M, Vega VB, Wong E, Orlov YL, Zhang W, Jiang J, et al. 2008. Integration of external signaling pathways with the core transcriptional network in embryonic stem cells. Cell 133: 1106-1117.

Cheung M, Abu-Elmagd M, Clevers H, Scotting PJ. 2000. Roles of Sox4 in central nervous system development. Brain Res Mol Brain Res 79: 180-191.
Collignon J, Sockanathan S, Hacker A, Cohentannoudji M, Norris D, Rastan S, Stevanovic M, Goodfellow PN, Lovellbadge R. 1996. A comparison of the properties of Sox-3 with Sry and two related genes, Sox-1 and Sox-2. Development 122: 509-520.

Efroni S, Duttagupta R, Cheng J, Dehghani H, Hoeppner DJ, Dash C, Bazett-Jones DP, Le Grice S, McKay RD, Buetow $\mathrm{KH}$, et al. 2008. Global transcription in pluripotent embryonic stem cells. Cell Stem Cell 2: 437-447.

Favaro R, Valotta M, Ferri AL, Latorre E, Mariani J, Giachino C, Lancini C, Tosetti V, Ottolenghi S, Taylor V, et al. 2009. Hippocampal development and neural stem cell maintenance require Sox2-dependent regulation of Shh. Nat Neurosci 12: 1248-1256.

Ferri ALM, Cavallaro M, Braida D, Di Cristofano A, Canta A, Vezzani A, Ottolenghi S, Pandolfi PP, Sala M, DeBiasi S, et al. 2004. Sox2 deficiency causes neurodegeneration and impaired neurogenesis in the adult mouse brain. Development 131: 3805-3819.

Gaspar-Maia A, Alajem A, Polesso F, Sridharan R, Mason MJ, Heidersbach A, Ramalho-Santos J, McManus MT, Plath K, Meshorer E, et al. 2009. Chdl regulates open chromatin and pluripotency of embryonic stem cells. Nature 460: 863-868.

Graham V, Khudyakov J, Ellis P, Pevny L. 2003. SOX2 functions to maintain neural progenitor identity. Neuron 39: 749-765.

Guenther MG, Levine SS, Boyer LA, Jaenisch R, Young RA. 2007. A chromatin landmark and transcription initiation at most promoters in human cells. Cell 130: 77-88.

Guth SIE, Wegner M. 2008. Having it both ways: Sox protein function between conservation and innovation. Cell Mol Life Sci 65: 3000-3018.

Hoser M, Potzner MR, Koch JMC, Bösl MR, Wegner M, Sock E. 2008. Sox12 deletion in the mouse reveals non-reciprocal redundancy with the related Sox 4 and Sox 11 transcription factors. Mol Cell Biol 28: 4675-4687.

Kamachi Y, Uchikawa M, Kondoh H. 2000. Pairing SOX off: With partners in the regulation of embryonic development. Trends Genet 16: 182-187.

$\mathrm{Ku} \mathrm{M}$, Koche RP, Rheinbay E, Mendenhall EM, Endoh M, Mikkelsen TS, Presser A, Nusbaum C, Xie X, Chi AS, et al. 2008. Genomewide analysis of PRC1 and PRC2 occupancy identifies two classes of bivalent domains. PLOS Genet 4: e1000242. doi: 10.1371/journal.pgen.1000242.

Liber D, Domaschenz R, Holmqvist PH, Mazzarella L, Georgiou A, Leleu M, Fisher AG, Labosky PA, Dillon N. 2010. Epigenetic priming of a pre-B cell-specific enhancer through binding of Sox2 and Foxd3 at the ESC stage. Cell Stem Cell 7: 114-126.

Magnani L, Eeckhoute J, Lupien M. 2011. Pioneer factors: Directing transcriptional regulators within the chromatin environment. Trends Genet 27: 465-474.

Malas S, Postlethwaite M, Ekonomou A, Whalley B, Nishiguchi S, Wood H, Meldrum B, Constanti A, Episkopou V. 2003. Soxl-deficient mice suffer from epilepsy associated with abnormal ventral forebrain development and olfactory cortex hyperexcitability. Neuroscience 119: 421-432.

Marson A, Levine SS, Cole MF, Frampton GM, Brambrink T, Johnstone S, Guenther MG, Johnston WK, Wernig M, Newman J, et al. 2008. Connecting microRNA genes to the core transcriptional regulatory circuitry of embryonic stem cells. Cell 134: 521-533.

Meshorer E, Yellajoshula D, George E, Scambler PJ, Brown DT, Misteli T. 2006. Hyperdynamic plasticity of chromatin proteins in pluripotent embryonic stem cells. Dev Cell 10: 105-116.

Mikkelsen TS, Ku M, Jaffe DB, Issac B, Lieberman E, Giannoukos G, Alvarez P, Brockman W, Kim TK, Koche RP, et al. 2007. 
Genome-wide maps of chromatin state in pluripotent and lineage-committed cells. Nature 448: 553-560.

Miyagi S, Masui S, Niwa H, Saito T, Shimazaki T, Okano $\mathrm{H}_{\text {, }}$ Nishimoto M, Muramatsu M, Iwama A, Okuda A. 2008. Consequence of the loss of Sox 2 in the developing brain of the mouse. FEBS Lett 582: 2811-2815.

Pevny LH, Nicolis SK. 2010. Sox2 roles in neural stem cells. Int $J$ Biochem Cell Biol 42: 421-424.

Pevny LH, Sockanathan S, Placzek M, Lovell-Badge R. 1998. A role for SOX1 in neural determination. Development 125: 1967-1978.

Ram EV, Meshorer E. 2009. Transcriptional competence in pluripotency. Genes Dev 23: 2793-2798.

Sandberg M, Källstrom M, Muhr J. 2005. Sox21 promotes the progression of vertebrate neurogenesis. Nat Neurosci 8: 9951001.

Schepers GE, Taesdale RD, Koopman P. 2002. Twenty pairs of Sox: Extent, homology, and nomenclature of the mouse and human Sox transcription factor families. Dev Cell 3: 167170.

Smale ST. 2010. Pioneer factors in embryonic stem cells and differentiation. Curr Opin Genet Dev 20: 519-526.

Sock E, Rettig SD, Enderich J, Bösl MR, Tamm ER, Wegner M. 2004. Gene targeting reveals a widespread role for the highmobility-group transcription factor Sox11 in tissue remodeling. Mol Cell Biol 24: 6635-6644.

Takahashi K, Yamanaka S. 2006. Induction of pluripotent stem cells from mouse embryonic and adult fibroblast cultures by defined factors. Cell 126: 663-676.

Taranova OV, Magness ST, Fagan BM, Wu Y, Surzenko N, Hutton SR, Pevny LH. 2006. SOX2 is a dose-dependent regulator of retinal neural progenitor competence. Genes Dev 20: 1187-1202.

Thein DC, Thalhammer JM, Hartwig AC, Crenshaw EB 3rd, Lefebvre V, Wegner M, Sock E. 2010. The closely related transcription factors Sox4 and Sox11 function as survival factors during spinal cord development. I Neurochem 115: 131-141.

Uchikawa M, Kamachi Y, Kondoh H. 1999. Two distinct subgroups of Group B Sox genes for transcriptional activators and repressors: Their expression during embryonic organogenesis of the chicken. Mech Dev 84: 103-120.

Wegner M. 2010. All purpose Sox: The many roles of Sox proteins in gene expression. Int I Biochem Cell Biol 42: 381-390.

Wegner M, Stolt CC. 2005. From stem cells to neurons and glia: A soxist's view of neural development. Trends Neurosci 28: 583-588.

Werner MH, Burley SK. 1997. Architectural transcription factors: Proteins that remodel DNA. Cell 88: 733-736.

Xu J, Watts JA, Pope SD, Gadue P, Kamps M, Plath K, Zaret KS, Smale ST. 2009. Transcriptional competence and the active marking of tissue-specific enhancers by defined transcription factors in embryonic and induced pluripotent stem cells. Genes Dev 23: 2824-2838. 


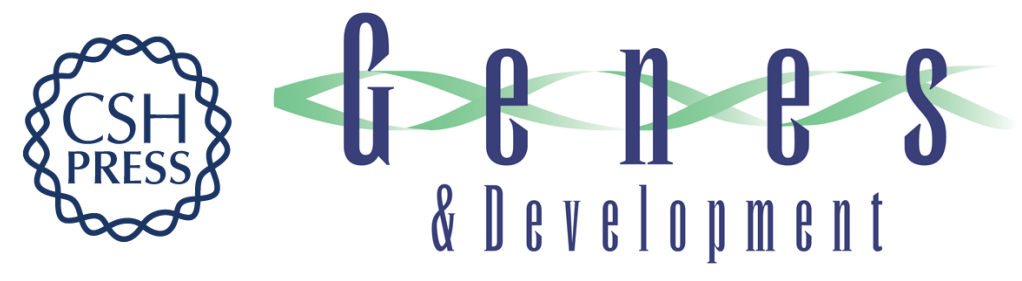

\section{SOX after SOX: SOXession regulates neurogenesis}

Michael Wegner

Genes Dev. 2011, 25:

Access the most recent version at doi:10.1101/gad.181487.111

Related Content Sequentially acting Sox transcription factors in neural lineage development Maria Bergsland, Daniel Ramsköld, Cécile Zaouter, et al.

Genes Dev. December , 2011 25: 2453-2464

References This article cites 42 articles, 11 of which can be accessed free at:

http://genesdev.cshlp.org/content/25/23/2423.full.html\#ref-list-1

Articles cited in:

http://genesdev.cshlp.org/content/25/23/2423.full.html\#related-urls

\section{License}

Email Alerting

Receive free email alerts when new articles cite this article - sign up in the box at the top Service right corner of the article or click here.

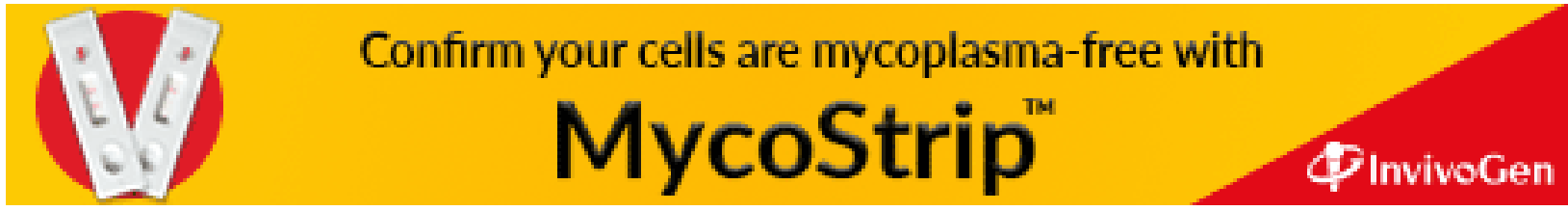

